\title{
ATELLLE
}

\section{Cura ut Valeas! Múltiplos usos e faces das máscaras em tempos de pandemia}

\author{
Cure ut Valeas! Multiple uses and faces of masks in \\ pandemic times
}

\section{Cure ut Valeas! Multiples utilisations et visages des masques pendant la pandémie}

\author{
Rosemere Maia \\ Universidade Federal do Rio de Janeiro \\ rosemaia@terra.com.br \\ Carlos Eduardo Santos Maia \\ Universidade Federal de Juiz de Fora \\ calrmaia@uol.com.br
}

\begin{abstract}
Resumo
A COVID19, pandemia que se alastra "oficialmente" pelo planeta desde janeiro do ano em curso, não só tem provocado vítimas como também evidenciado a necessidade de adoção de medidas de proteção por parte de diversos profissionais e da população em geral. No presente artigo, objetiva-se abordar o uso de máscaras em espaços públicos e privados de uso coletivo, onde tal equipamento se impõe como fundamental para proteção e contenção do coronavírus. Antes, porém, faz-se uma análise acerca do uso de máscara em outros espaços-tempos, enfocando-se alguns de seus significados e simbologias naqueles contextos sociais. Metodologicamente, o texto se baseia em pesquisa bibliográfica e documental de diversas fontes (sites, livros, revistas, reportagens, blogs). Nas conclusões, apresentam-se principalmente alguns questionamentos ao invés de proposituras fechadas e antecipadas, proposituras estas não condizentes com a prevalência de tantas incertezas.

Palavras-chave: COVID-19, Pandemia, Espaço Público, Espaço Privado de Uso Coletivo.
\end{abstract}

\begin{abstract}
The COVID-19 pandemic has been "officially" spreading across the planet since January this year. This disease has provoked victims and highlighted the need for the adoption of protective measures by various professionals and the population in general. This article aims to discuss the use of masks in public and private spaces for collective use where such tool is fundamental for the protection and containment of the
\end{abstract}


coronavirus. However, before starting the discussion, we analyze the use of masks in other space-times, focusing on some of their meanings and symbologies in those social contexts. In terms of methodology, the research is based on bibliographic and documentary research from different sources (websites, books, magazines, reports, and blogs). On the conclusions, some questions are presented instead of closed and anticipated propositions, propositions that are not consistent with the prevalence of so many uncertainties.

Keywords: COVID-19, Pandemic, Public Space, Private space for collective use.

\begin{abstract}
Résumé
La COVID19, pandémie qui se répand sur toute la planète «officiellement» depuis le mois de janvier de cette année, a fait d'innombrables victimes mais a aussi fait apparaître l'impérieuse nécessité de mettre en place des mesures de protection dans de nombreuses professions et dans la population en général. Cet article se propose d'aborder l'emploi de masques dans les espaces publics et privé à usage collectif où cet équipement se montre essentiel pour la protection des individus et pour endiguer le coronavirus. Mais avant cela, on fera un rapide analyse de l'utilisation du masque dans d'autres espaces-temps, centrée sur quelques-unes de ses significations et de ses symbologies dans ces contextes sociaux. Du point de vue méthodologique, le texte s'appuie sur une recherche bibliographique et documentaire auprès de diverses sources (sites internet, livres, revues, reportages, blogs). Les conclusions offrent plutôt des interrogations que des thèses abouties et prématurées, hors de propos face à tant d'incertitudes.
\end{abstract}

Mots-clés: COVID-19, pandémie, espace public, espace privé à usage collectif.

\title{
Introdução
}

Em meio a todo horror provocado pela COVID19 - essa pandemia que, desde janeiro de 2020, vem assombrando a população do planeta e provocando inúmeras vítimas - um assunto entrou na ordem do dia: o uso de máscaras nos espaços públicos e privados de uso coletivo.

Em que pese a importância do debate no contexto epidemiológico sobre as máscaras como Equipamentos de Proteção Individual (EPI)- tais como são classificadas pelas organizações/instituições de saúde-, no presente texto são trazidas à luz algumas questões relativas a tais artefatos na qualidade de códigos simbólicos relacionados a questões sócio-espaciais ${ }^{1}$, culturais, políticas e de saúde pública, que não são antagônicas à sua materialidade como EPI.

As máscaras aqui são vistas como elementos de proteção, mas também possuidoras de potencial de esconder e desvelar; distinguir e igualar; segregar e agrupar; o que nem sempre é visível de maneira imediata, embora isto seja fundamental para a compreensão do papel social que elas assumem num momento em que o mundo se encontra voltado ao combate ao coronavírus SARS-CoV-2 e à doença por ele provocada, a COVID-19.

\footnotetext{
${ }^{1}$ Adotamos sócio-espacial (com hífen), ainda que contrariando o previsto no Acordo Ortográfico da Língua Portuguesa (1990), a partir da discussão feita por Souza (2007).
} 


\section{Máscaras ontem e hoje: quando a história se repete ora como tragédia, ora como comédia}

O uso de máscaras é tão antigo quanto as práticas ritualísticas humanas e, por esta razão, elas têm importância sine qua non para a análise do significado do "ser humano". Ao longo dos séculos (ou milênios) e em todas as civilizações foram utilizadas para os mais variados fins em diferentes rituais, representando divindades, seres sobrenaturais, arquétipos sociais e mortos ilustres, deixando clara sua associação estreita com distintos espaços-tempos, com crenças e com motivações transcendentais do grupo social onde se originou. Por estarem amplamente associadas a práticas ritualísticas, seus usos implicam em direcionamentos e posicionamentos espaciais próprios, conteúdo emocional, agenciamentos, deslizes de fronteiras e identificações coletivas em co-presença, como nota Maia (2010) acerca da "geograficidade" dos rituais baseado em Parkin e outros autores.

Os homens "primitivos", de acordo com registros em pinturas rupestres, já lançavam mão deste artefato durante suas caçadas, muito provavelmente crendo no seu poder de atração ou de proteção frente ao animal. Klintowitz nota que, nas sociedades "primitivas", por ele chamadas de ritualísticas, "o uso de máscaras [...] é extremamente preciso. A máscara significa o espírito, o sopro inatingível, o imaterial, o espírito vital da natureza". Nestes agrupamentos sociais, em que o tempo é apreendido de modo "circular e a cada ciclo - solar, lunar, agrícola - a comunidade retorna ao marco zero", o autor observa que "a utilização da máscara [...] realiza [...] intercâmbio entre a cultura e o mito, entre o sistema social e a origem e hierarquia mítica" e, diríamos, entre cultura (religiosa, alimentar, medicinal, festiva, etc.) e natureza (caça, coleta, colheita, "controle" de fenômenos atmosféricos, etc.). A máscara, assim, estabelece um elo entre espaço-tempo social e universo mítico, onde "os valores míticos, mágicos e humanos integram-se numa atividade essencial ao equilíbrio da comunidade” (KLINTOWITZ, 1986, p. 7-8).

$\mathrm{Na}$ Antiguidade Egípcia, a máscara não era utilizada como disfarce ou dissimulação das feições do rosto, mas sim como instrumento capaz de elevar seu portador a um nível de divindade, após a morte. Oliveira (2016) também menciona a sua funcionalidade no mundo dos vivos, pois servia aos sacerdotes responsáveis pelo embalsamamento dos corpos. Neste ritual, a máscara invocava o poder de Anúbis (o deus da mumificação) e protegia dos odores que emanavam dos corpos e de produtos necessários a tal procedimento. Vemos, em meio à atual pandemia, não embalsamadores de corpos, mas agentes funerários e coveiros em pleno uso de tal artefato numa tentativa de proteção frente ao vírus (Figura 01). Corpos não são embalsamados, mas enrolados em sacos plásticos e colocados em urnas fechadas, às vezes sem haver cerimônia de funeral, sem qualquer ritual de despedida de familiares, sendo muitos deles postos em covas rasas. 


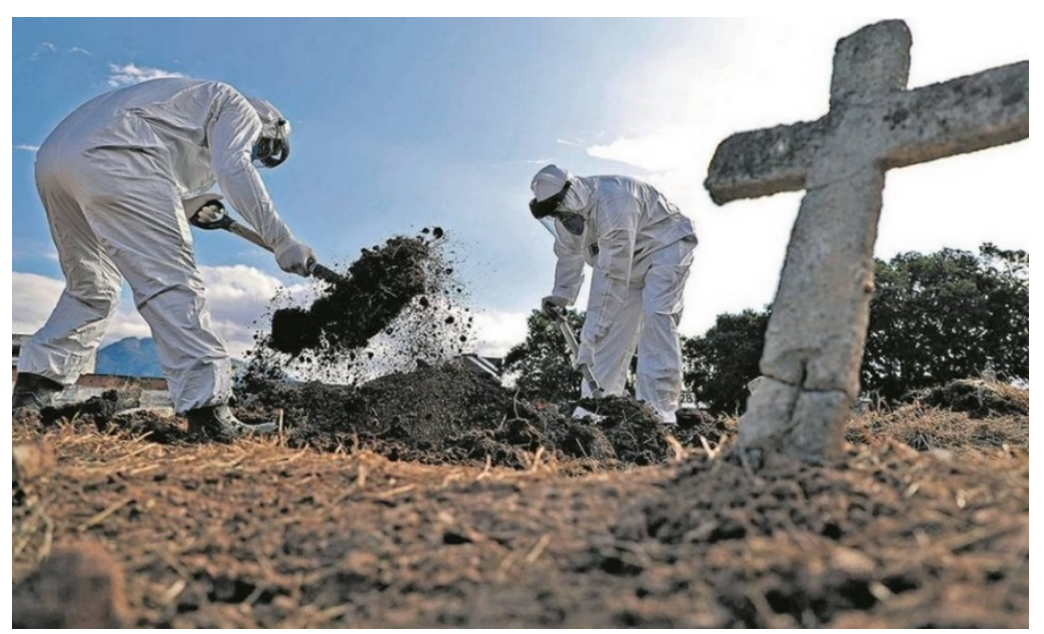

Figura 01: Coveiros utilizam equipamentos de proteção individual (EPI) durante sepultamento de vítima da COVID19.

Fonte: Motta, 2020.

Na China, o uso de máscaras remonta a eras muito pretéritas, fazendo parte de sua tradição. Há registros históricos de sua utilização há, pelo menos, 3.500 anos A.P (até o presente), numa evidente associação a rituais religiosos e de cura, às celebrações de passagem de ano e à arte - como nas óperas e no teatro. Hoje este é o país que mais produz máscaras de proteção e, igualmente, talvez seja um daqueles onde seu uso já se encontrava mais disseminado como medida de saúde pública, mesmo antes desta pandemia. Num contexto onde a poluição é um grande problema urbano e há quase uma centena e meia de cidades com mais de um milhão de habitantes, a máscara já foi assimilada ao dia a dia dos chineses, sendo vista como fundamental à proteção contra poluentes e viroses.

$\mathrm{Na}$ Grécia antiga, a máscara não era algo que escondesse a identidade de alguém. Era o prosopon, aquilo que se apresentava à vista dos outros, o que se podia olhar (ALTUNA, 2009). Os gregos não viam a máscara como um elemento de dissimulação, mas sim de identificação e representação. Ela anulava a personalidade/a identidade do ator, assumindo um conteúdo simbólico importante, posto referir-se a uma categoria humana, a uma classe social ou a uma figura heroica, conforme afirma Moreira (1994). Hoje, em plena pandemia, ela incorpora tal potencial, sobretudo nos "campos de guerra" que se tornaram os hospitais, onde o prosopon identifica os protagonistas que estão na linha de frente do combate ao coronavírus (médicos, enfermeiros e demais profissionais de saúde) - muitas vezes dispondo de recursos precários. Os guerreiros que estão no front desta batalha - e que, segundo a própria OMS, deveriam dispor de equipamentos de proteção individual (dentre eles a máscara) -, muitas vezes já se identificam, por força das circunstâncias, com personagens fadados à derrota em meio ao drama contemporâneo que se tornou a pandemia provocada pelo SARS-CoV-2, a exemplo do que é demonstrado em trecho da matéria abaixo: 


\begin{abstract}
O perigo para quem está na linha de frente é enorme porque ao trabalhar diretamente com os doentes os profissionais de saúde recebem uma carga de vírus e podem, por isso, desenvolver as formas graves da doença. As queixas se multiplicam no país. O Conselho Federal de Enfermagem já recebeu quase 3,6 mil denúncias de falta, escassez ou má qualidade dos equipamentos de proteção individual como máscaras, luvas e aventais. (G1-GLOBO, 2020 ).
\end{abstract}

No mundo grego são memoráveis as simbólicas máscaras de tragédia e de comédia, amiúde relacionadas ao nascimento do teatro por ocasião das festas dionisíacas. Atribui-se a Thespis de Icaria e/ou a Ésquilo, no século VI a.C., a invenção da tragédia teatral e de suas máscaras, havendo, porém, polêmicas em relação a tais autorias (THEATRONS, 2020; LYCEEDADULTES, 2020). Etimologicamente tragédia deriva de tragōidía que significa ode/canto ao bode, referindo-se a um ritual para Dionísio no qual se cantava e sacrificava-se o animal.

Em termos teatrais, as tragédias eram representações - na maioria das vezes, relacionadas à mitologia- com livre interpretação textual implicada de questões políticas e metafísicas, tornando-se assunto deste gênero teatral "mostrar personagens das mitologias vítimas do destino, da fatalidade" (LYCEEDADULTES, 2020 - tradução dos autores). Buscava-se, nas tragédias, um sentimento catártico em que os espectadores encontrassem identificação com as personagens, tendo "as mesmas paixões que eles, fazendo-as exteriorizar (...) e delas se libertar" (LYCEEDADULTES, 2020 - tradução dos autores).

No contexto da COVID19, pode-se considerar a tragédia na qualidade de uma encenação que espetaculariza as máscaras do poder. Neste momento de pandemia, representantes da alta classe política colocam e tiram máscaras preventivas, às vezes de modo burlesco, para dar entrevistas e perambular de maneira politiqueira na multidão. Colocam as máscaras numa representação de "tementes a Deus", "gente igual aos outros", "defensores da ordem" (econômica), "da Constituição", etc. Caras novas entram e saem de ministérios, secretarias de saúde, direções de hospitais, como se isto fosse apenas uma troca de máscara. As máscaras do poder têm incitado o afloramento de paixões entre espectadores que defendem ou condenam o distanciamento social a partir de tal ou qual partido e/ou facção política, e mesmo entre dirigentes que editam medidas/decretos que prescrevem ou proscrevem o uso destes artefatos de proteção em determinados espaços (espaços públicos, templos religiosos, estabelecimentos comerciais, presídios, etc.), não necessariamente ancorados em dados oriundos da Ciência, mas sim de preceitos ideológicos e políticos (quiçá religiosos). Mas quem servirá de bode expiatório ao sacrifício em meio a estas disputas? Serão as classes privilegiadas em sua ocupação dos espaços públicos nas "trágicas carreatas"? Ou serão os segmentos populares que seguem espremidos nos transportes coletivos, segregados nas favelas, desamparados nas calçadas e cujo cotidiano é marcado por toda sorte de carências, expressando a desigualdade sócio-espacial que marca a sociedade brasileira?

Já na comédia, que etimologicamente deriva de kōmōidía (referência à poesia satírica), "canto ao cosmos" (STUDYLIBFR, 2020), colocavam-se em cena as falhas da vida dos homens e da sociedade, com sátiras às figuras públicas de modo caricaturado. O objetivo da comédia, cuja criação é atribuída a Aristófanes, no século V, era (é) provocar o riso; em 
efeito, suas máscaras acentuavam o ridículo de modo extravagante (THEATRONS, 2020; ESPACEFRANCAIS, 2020; LYCEEDADULTES, 2020). Se na tragédia buscava-se aquele sentimento catártico pelo medo, a comédia almejava "conscientizar o espectador dos principais problemas da existência através do riso" (STUDYLIBFR, 2020 - tradução dos autores). A comédia, agora, permite ao cidadão rir daqueles que se travestem com as máscaras do poder e mesmo do uso da máscara da pandemia; o que, nessa era da internet, tem nos memes, viralizados em escala global no ciberespaço, a ferramenta principal de expressão do riso. Um estudo realizado pela pesquisadora Maria Carolina Avis, docente do curso de Marketing Digital do Centro Universitário Internacional, demonstra que os memes têm ajudado os brasileiros no enfrentamento da quarentena, justamente pelo conteúdo divertido que ele apresenta. Mas os dados da pesquisa demonstram que, nas redes sociais, eles superam, em frequência, os conteúdos de caráter estritamente informativos (34\% para os primeiros, em contraposição a $17 \%$ para os demais). Isso não significa desconsiderar o papel que tais conteúdos humorísticos possuem de informação. Para a pesquisadora, "embora os memes sejam uma forma divertida e informal de conteúdo, eles podem, sim, servir para educar e disseminar informações de qualidade como dar dicas e deixar mensagens positivas de forma descontraída" (DEOLHONOFUTURO.UNINTER, 2020). E assim tem sido no que se refere ao uso (ou mau uso) das máscaras (Figura 02).
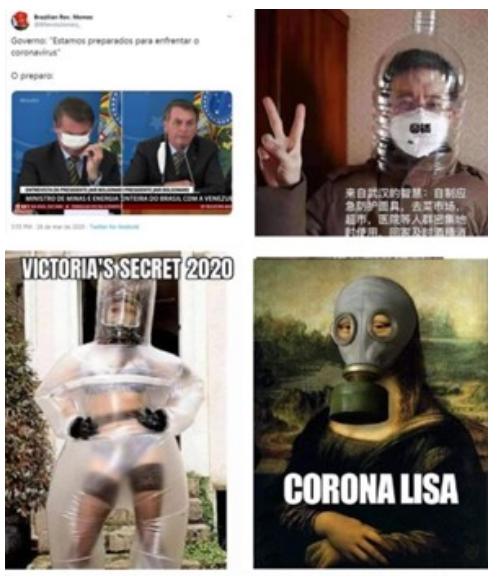

Je me fous de qui est votre père, ce rassemblement est illégal.

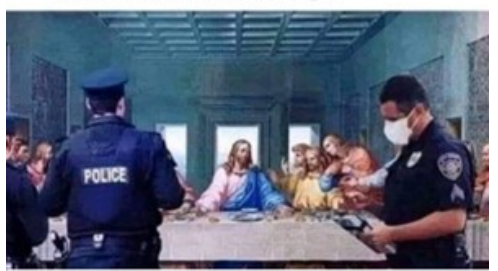

Figura 02: A Comédia dos Memes Fonte: Internet (autores desconhecidos) 
$\mathrm{Na}$ Itália, são famosas as máscaras de Veneza, cuja origem é remota, mas costuma-se protocolar seu surgimento no início do século XIII, em 1204, a ponto de, em 1268, já haver um decreto proibindo pessoas mascaradas de jogarem ovos pelas janelas durante o carnaval (BERTRAND, 2013, p. 27). Atualmente, entre as fantasias e as máscaras comuns no carnaval de Veneza estão as de "médico da peste" (Figura 03). Todavia, esta não é uma máscara, tampouco uma fantasia tipicamente veneziana, mas se refere ao traje criado pelo médico francês Charles de l'Orme, em 1619, composto por longa túnica impermeável, bastão (a fim de evitar o contato direto com os doentes), sapatos, luvas e chapéu (Figura 04). No rosto, colocavam-se óculos sobre uma máscara com um bico comprido e cheio de gaze embebida com óleos essenciais e vinagre, além de ervas aromáticas, objetivando proteger o médico dos "miasmas", supostamente difusores da peste (THEMASCHERADE, 2020; MUSEUMPASSMUSEES, 2020). Ou seja, pode-se fazer uma analogia da máscara/traje de "médico da peste" à maneira de EPI do século XVII. Interessante mencionar, ainda, que durante o carnaval de 2020 (quando a pandemia se apresentava como uma realidade ainda "distante" para nós, brasileiros), houve apropriação cultural da máscara hospitalar relacionada ao coronavírus por foliões de blocos, que a transformaram em elemento de fantasia (Figura 05), o que provavelmente será tendência ainda para o carnaval de 2021 - mas não se pode cogitar que isto permaneça por quatro séculos, tal qual ocorre com a fantasia do "médico da peste".

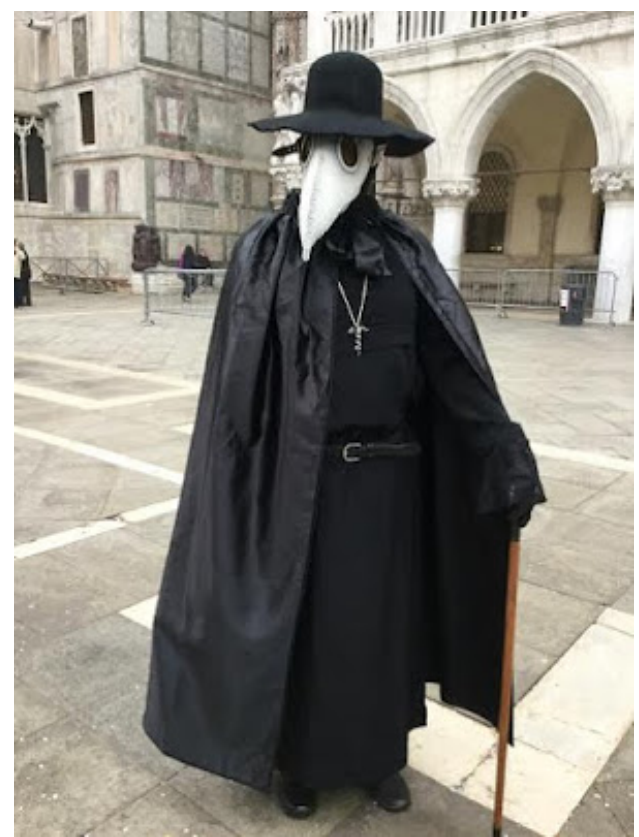

Figura 03: Fantasia de Médico da Peste no Carnaval de Veneza

Fonte: Bauer, 2016. 


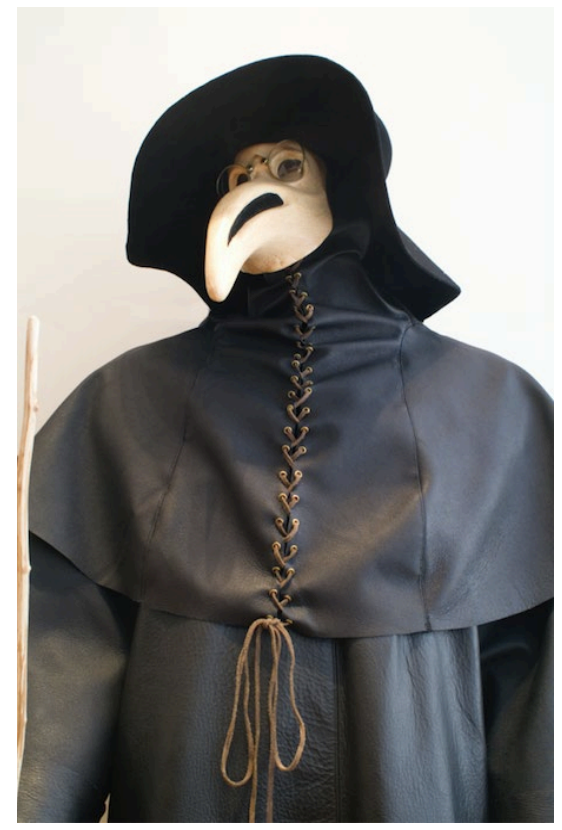

Figura 04: Traje de Médico da Peste exposto no Hospital Notre-Dame à Rosa Fonte: VAUBAN, 2018.

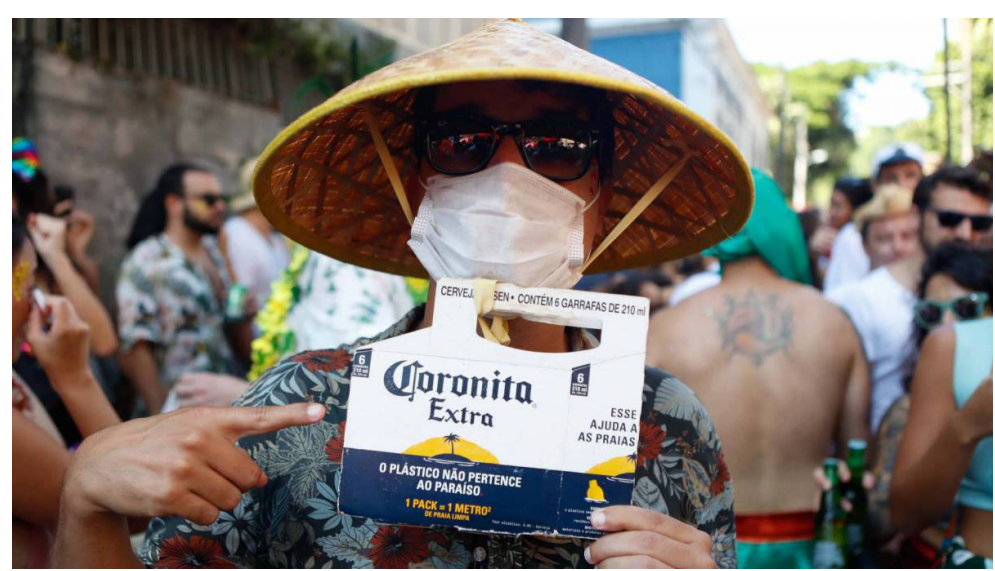

Figura 05: Máscara hospitalar "fantasia de Corona Vírus" Fonte: SOUZA, 2020.

Poderíamos, aqui, elencar um sem número de usos e funções atribuídos às máscaras ao longo da história e sua "geograficidade", mas o escopo do presente texto não nos permite voo tão alto. Nosso objetivo, nestas rápidas pinceladas, é demonstrar que não é possível falar de máscara extraindo deste artefato seu caráter espaço-temporal, tanto 
quanto seus conteúdos simbólico, dramático e comunicacional. A despeito do sentido que lhe é atribuído por aquele que a concebe - ou seja, da ideia original -, é fato que ela "ganha autonomia na forma e passa a existir independentemente do seu criador, sem, no entanto, perder a relação direta com nossa sensibilidade, inteligência e bagagem cultural", conforme sugerido por Dani (1990, p. 83). Assim, contemporaneamente, em contraste com aquelas sociedades "ritualísticas" que se falou no início desta parte, de tempo circular que, a cada ciclo, retorna ao marco zero, vivemos em sociedades industriais cujas referências simbólicas são bem distintas: o tempo é histórico e progressivo - "no qual o posterior sempre sucede o anterior", de acordo com Klintowitz (1986, p.14). Tal perspectiva tem gerado afirmações/suposições (sustentadas por especialistas ou veiculadas pela mídia) de que o mundo não será o mesmo após esta pandemia; ou seja, não retornaremos ao marco zero de 10 de janeiro de 2020, dia anterior à primeira morte oficialmente registrada e imputada ao coronavírus. No Brasil, incorporaremos as máscaras como elemento cotidiano protetor nos espaços públicos e privados de uso coletivo à maneira de alguns povos orientais? Que novas formas de controle sanitário mundiais teremos?

\section{Guerre des masques: salve-se quem puder!}

Observando o momento por que passamos - onde a proteção frente a um inimigo invisível que a todos ameaça se apresenta como necessária -, cremos que a crescente imposição (ou recomendação) do uso de máscaras a toda população tende a impactar diretamente na saúde pública, mas também na economia, na política, na dinâmica citadina, na sociabilidade, no estabelecimento de hierarquias sociais, no aprofundamento de desigualdades. Dada a falta de previsão quanto aos desdobramentos e à duração da pandemia, fica difícil igualmente prever se o uso de máscaras permanecerá como orientação ou como hábito higiênico/preventivo social, tal qual já ocorre com os povos orientais (chineses e japoneses, principalmente) que fazem delas itens de proteção de doenças (resfriados, gripes, alergias, pneumonia), recurso para distanciamento social, ou até artigo fashion (logo, associado ao mercado da moda).

No Brasil, foi por volta da terceira semana de crescimento exponencial do número de infectados e mortos pela COVID19, que o Ministério da Saúde resolveu indicar o uso de máscara como necessário à contenção da pandemia, acompanhando (talvez tardiamente) o que já vinha acontecendo em outros países. Até então, somente aos profissionais de saúde e de segurança e aos pacientes infectados tal recomendação era feita. Entretanto, esta orientação veio seguida pela constatação de que o mercado mal dispunha de condições de atender à demanda apresentada pelos serviços de saúde, tornando impensável a universalização do acesso a tal equipamento de forma massiva pela população. Mais que isso, percebeu-se que, pelo fato de o Brasil depender da importação do produto, precisaria entrar na disputa global à qual os franceses chamaram de guerre des masques (guerra das máscaras).

A guerra que foi declarada - sem regras muito claras - colocou, a partir daí, os países em concorrência por um item que se tornou extremante valioso, levando alguns 
governantes à adoção de medidas extremas, como o confisco de mercadoria, a cobertura de preço (transformando a comercialização das máscaras num negócio muito parecido com um leilão, onde leva quem pode pagar mais), o recurso a leis que permitem o direcionamento da produção para o atendimento exclusivo às demandas do mercado interno. O exemplo mais emblemático vem dos EUA, onde Trump, ao lançar mão da Lei de Produção de Defesa, de 1950 (o que já era de se esperar, em virtude da doutrina que propaga: America First), tem demonstrado total falta de empatia ou, no mínimo, de preocupação com a situação de países que, tradicionalmente, foram seus aliados, bem como com a saúde pública em escala global. O que importa, nesta guerra mundial de combate ao coronavírus é, mais uma vez, mostrar que os EUA dispõem de uma arma poderosa para conseguir EPI, respiradores e kit de testes: o dinheiro - embora todos os recursos conseguidos por meio do que se chamou- até de "pirataria moderna" não serem capazes de tornar os americanos menos vulneráveis aos danos provocados pelo vírus que assolou principalmente Nova York, colocando os EUA no topo do ranking de contaminados e mortos, e demonstrando não só a fragilidade e os problemas da não universalidade do seu sistema de saúde, mas principalmente a enorme desigualdade que grassa na maior potência econômica mundial. Note-se que, num erro estratégico, talvez motivado pela subestimação do poder de disseminação da COVID-19 e seus impactos na saúde pública e na mortandade dos contaminados, os EUA exportaram para a China em ventiladores e roupas de proteção nos meses de janeiro e fevereiro de 2020 US\$ 17,6 milhões, enquanto no mesmo período, no ano de 2019, este valor somou US\$1,4 milhões (EILPERIN et Al., 2020).

Outra mudança significativa no campo da economia tem sido a alteração de foco, no que se refere à produção, por parte de algumas empresas. Não somente daquelas que buscam, voluntariamente, a manutenção da produtividade diante da crise apresentada, mas de outras que, por força de leis e decretos, ou mesmo atendendo a orientações governamentais, tiveram que alterar/converter sua cadeia produtiva, deixando de fabricar equipamentos automotivos, smartphones, vestuário, fraldas descartáveis e passando a produzir respiradores, máscaras e outros componentes de EPI. É o capitalismo se "reinventando" em meio a uma nova crise.

No campo da informalidade, as máscaras também se apresentam como alternativa de renda para os trabalhadores. Dado o crescimento exponencial do número de infectados em todo o país e a busca por proteção (seguindo orientações ou determinações oriundas da OMS, do Ministério da Saúde ou de governos estaduais e municipais), o acesso às máscaras caseiras colocou-se como única alternativa ao cidadão comum. Em entrevista coletiva, realizada no dia $1^{\circ}$ de abril, o ex-Ministro da Saúde, Luís Henrique Mandetta, sustentou: "Qualquer pessoa pode fazer sua máscara de pano e utilizar, que vai estar ajudando o sistema de saúde". Na mesma entrevista, ele enfatizou o baixo custo para a confecção dos acessórios. A partir daí, a produção e a venda de máscaras passaram a "aquecer" a economia informal. Muitos trabalhadores, impactados em suas atividades diaristas, ambulantes, vendedores de "quentinhas", barraqueiros, costureiras, etc.- viram nestes artefatos uma possível fonte de rendimentos, produzindo e vendendo máscaras simples, com estamparia diversa, ou grifadas com logos de times de futebol, escolas de 
samba, marcas de cerveja, etc. a fim de atraírem diferentes consumidores. Na cidade do Rio de Janeiro, inclusive, constata-se uma grande tolerância por parte da Guarda Municipal em relação aos informais que, embora ocupando ilegalmente o espaço público, comercializam máscaras de tecido. Percebe-se, assim, que no contexto da COVID-19 as máscaras assumiram naquelas famílias um papel de "colchão amortecedor da crise", num momento em que crescem o desemprego e o desalento.

\section{Bal Masqué - as máscaras ressignificadas em tempos de pandemia}

Saindo dos campos da Política e da Economia, pode-se dizer que as relações estabelecidas pelos citadinos também sofrem impactos expressivos em decorrência do avanço da pandemia. É patente que as cidades, sobretudo as grandes metrópoles, levam seus habitantes ao desenvolvimento de alguns mecanismos de defesa, tão bem descritos/analisados por Simmel (2005) e Wirth (1973): a impessoalidade, a indiferença, a reserva, a atitude blasé. Tornamo-nos anônimos, desenvolvemos uma racionalidade que nos permite estar próximos fisicamente, mas distantes emocionalmente. Em meio à multidão, não distinguimos rostos. Tornamo-nos quase parte de uma massa disforme (ou uniforme?). Se a "cidade grande" já impinge a seus habitantes tais comportamentos, ou como diria Simmel, "atitudes mentais", o que poderíamos dizer se agora a tendência é vermos faces cobertas, mascaradas, onde, retomando Simmel, "o sujeito se ajusta inteiramente por conta própria a essa forma de existência, a sua autoconservação frente à cidade grande exige-lhe um comportamento não menos negativo de natureza social" (2005, p. 582). Carlos observa que rostos de mortos são divulgados na imprensa, substituindo a impessoalidade dos números, mas a autora adverte que isto "[...] ainda é insuficiente. Os rostos da crise não são, assim, tão literais, apesar de criarem a empatia ao isolamento, humanizando uma sociedade individualista que vive sob o signo do 'hedonismo de massa"' (CARLOS, 2020, p. 1).

Nas cidades brasileiras, fora momentos extraordinários/festivos (carnaval, folias de reis, cavalhadas, etc.), o uso de máscaras não costumava ser usual. Em outros contextos/tempos, apresentavam-se como recursos utilizados por meliantes ou membros de facções criminosas para a prática de crimes, e mesmo por policiais visando o resguardo de sua identidade. Também se tornaram muito comuns em manifestações, como naquelas ocorridas em 2013, quando os "black blocs" vestidos de preto e com as faces cobertas demonstravam um sentimento generalizado de desprezo pelo Estado e pelas políticas econômicas neoliberais mediante táticas em geral classificadas como "violentas" e "anárquicas", realizando um ataque simbólico às instituições. De qualquer forma, nos campos aqui mencionados, havia certo elo da máscara à festa, à violência e/ou ao medo.

Agora, por conta de um inimigo que é imperceptível a olho nu, todos desconfiam de todos, alguns se afastam dos outros por não saberem se, por trás da máscara, há alguém contaminado ou, simplesmente, a pessoa em busca de proteção. Assim, sugere-se que a máscara possui um "valor comunicativo", de "sinal", tal qual sustentado Eco (1989, p.15). São esses valores que, a nosso ver, as máscaras de proteção contra o coronavírus também 
vêm assumindo, sendo ressignificadas nos espaços públicos, coletivos e mesmo domésticos. Nestes espaços - campos destinados ao ordinário, ao cotidiano -, as máscaras são equipamentos de proteção e diretriz de saúde pública, mas também parte do vestuário como peças de roupas à maneira de acessórios fundamentais para se ir à rua, transpondo as funções que lhe foram originalmente atribuídas. Neste sentido, é exemplar a referência feita por Eco ao traje de pele usado pelos homens primitivos, demonstrando que lá o vestuário já assumia um potencial distintivo - o que ocorre, atualmente, com as máscaras:

Tinha frio e se cobria, não há dúvida. Mas também não há dúvida que no espaço de poucos dias depois da invenção do primeiro traje de peles, se terá criado a distinção entre os bons caçadores, munidos das suas peles, conquistadas pelo preço de uma dura luta, e os outros, os inaptos, os sem-peles. E não precisa de muita imaginação para enxergar a circunstância social em que os caçadores terão envergado as peles, já não para proteger-se do frio, mas para afirmar que pertenciam à classe dominante (ECO, 1989, p. 15).

A escassez de máscaras é fato. A disputa por elas (inclusive em termos globais, como já mencionado) é uma realidade. Os preços daquelas que são recomendadas como mais eficientes para a proteção frente ao inimigo invisível são abusivos (isso quando há algum item disponível no mercado), chegando a 200 reais a unidade. Esses três elementos, individualmente, ou articulados, já se mostram como razões suficientes para nos diferenciar como "bons caçadores" ou "inaptos/sem-peles". Saindo do ambiente estrito da saúde (como hospitais e clínicas), a tendência é que se apresente uma população cujos membros também serão reconhecidos/discriminados nos espaços públicos e privados de uso coletivo pelo tipo de máscara utilizada, ou pelo não uso dela. Os "bons caçadores" serão aqueles que, detentores de maiores recursos financeiros, investirão algumas centenas de reais para ter acesso aos equipamentos adequados e mais protetivos; ao passo que os demais entrarão num processo de "viração", apelando para as "receitas caseiras", para as "saídas domésticas", para a "criatividade", com proteção nem sempre tão efetiva. Não podemos deixar de mencionar, entretanto, aqueles que permanecerão fora de qualquer uma dessas alternativas, posto que, socialmente, são relegados à invisibilidade ou, quando muito, classificados como "inaptos" e "vulneráveis". Neste rol, estariam os sem-teto e a população em situação de rua (que serão transmutados em "sem-máscaras"). Se antes da pandemia já despertavam incômodo onde quer que estivessem, agora, na qualidade de "sem-máscaras", maior sentimento de repulsa, de medo e de horror poderão provocar nos "mascarados", ao serem vistos como "vetores" potenciais da doença. Por outro lado, aos portadores de máscaras que se mostram assintomáticos pode-se dedicar aquela "desatenção civil" proposta por Goffman (2010) que é caracterizada pelo não temor e pela evitação (inclusive de se "olhar para").

Tudo isto nos permite, outrossim, tratar a máscara como vestimenta na pandemia, compreendendo-se que o vestir abrange, tal como propõem Thieme e Eicher (1987) forma material, ato de vestir e significado sociocultural. Como forma material tem-se a própria máscara, seu uso e sua manipulação intencional relacionados à saúde pública; o ato de vestir nos conduz à produção e à obtenção das máscaras e ainda aos limites estabelecidos 
pelos governos, de diferentes esferas, à ausência de seu uso nos espaços públicos e coletivos; já o significado sociocultural se reflete na máscara como variável indicadora da posição do indivíduo na sociedade no tocante à sua possibilidade de aquisição deste artefato, ou ainda no modo como os sujeitos encaram a pandemia - conforme temos abordado. Este conceito de vestir em Eicher e seguidores ventila a discussão proposta. Sobre isto, observa Melchior:

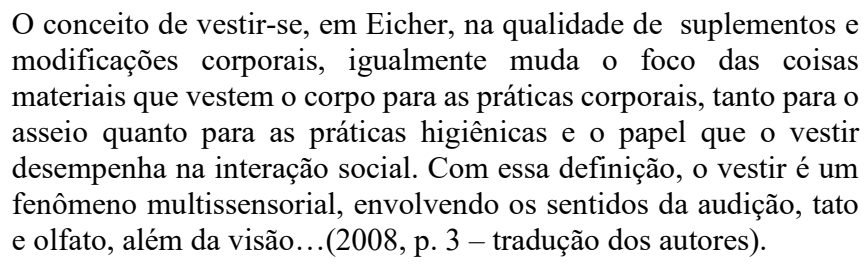

Assim, em sua expressão multissensorial, a máscara na pandemia nos veste expressando um novo medo.

\section{"Barrados no Baile"- Interdições, recomendações e apropriações quanto ao uso de máscaras no espaço citadino}

Em junho de 2013, quando grandes manifestações tomaram conta de muitas cidades brasileiras, medidas legais foram tomadas com o objetivo de coibir o uso de máscaras por manifestantes (Figura 06). Na Cidade do Rio de Janeiro foi sancionada a lei 6.528/2013 regulamentando o artigo 23 da Constituição do Estado e indicando, no que se refere a "reunião pública para manifestação de pensamento", no seu artigo $2^{\circ}$, ser "especialmente proibido o uso de máscara ou qualquer outra forma de ocultar o rosto do cidadão com o propósito de impedir-lhe a identificação" (RIO DE JANEIRO, 2013). Antes disso, no ano de 2008, o deputado Dionisio Lins apresentou à Assembleia Legislativa do Estado do Rio de Janeiro o Projeto de Lei No 1239/2008 que visava proibir a venda das fantasias de Clóvis ou Bate Bola (Figura 07), tradicionais do subúrbio e da periferia metropolitana do Rio de Janeiro, alegando que estas fantasias dificultavam a identificação dos usuários pelas autoridades ou demais pessoas (RIO DE JANEIRO, 2008a) e só poderiam ser utilizadas, com máscaras, por crianças. O relator do projeto na Comissão de Constituição e Justiça da ALERJ, Deputado Paulo Melo, deu parecer pela inconstitucionalidade do projeto observando, entre outros aspectos, que esta lei proibiria "uma máscara que é expressão da cultura carnavalesca carioca e permite o comércio de máscaras do dia das bruxas, expressão cultural importada" (RIO DE JANEIRO, 2008b). 


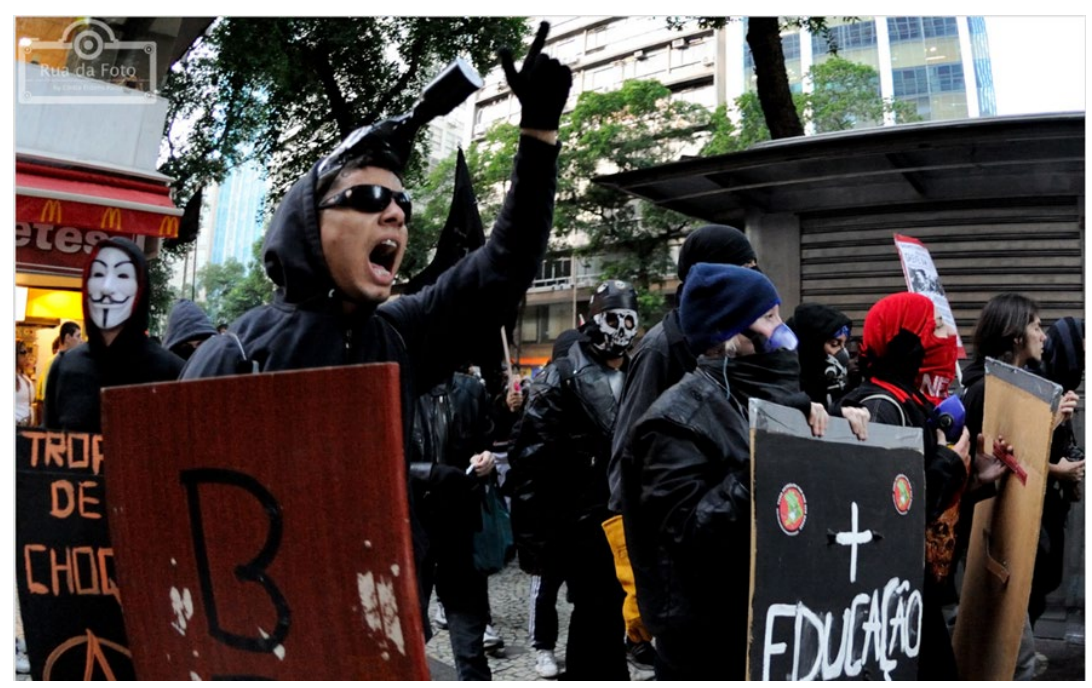

Figura 06: Protestos no Rio de Janeiro: "black blocs"

Fonte: PAIVA, 2013.
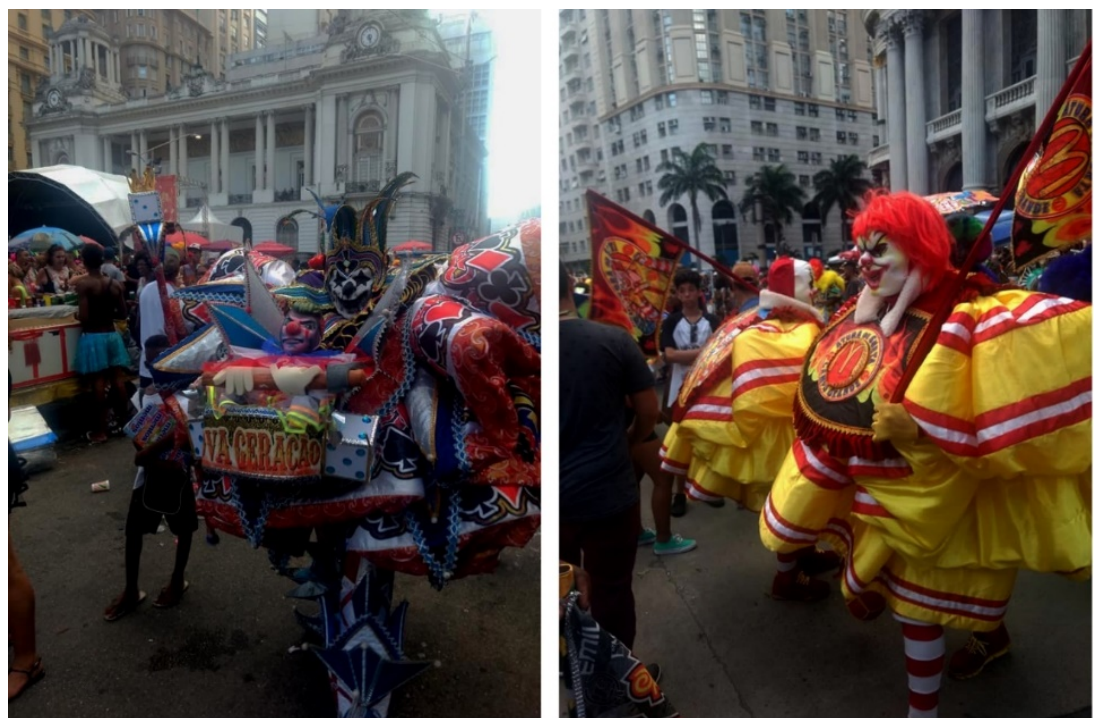

Figura 07: Clóvis (Bate Bola) carnaval Rio de Janeiro 2020

Fonte: Fotos dos Autores, 2020.

Atualmente o uso de máscara se coloca, mais uma vez, no centro de grandes polêmicas. Aos 19 de maio de 2020, o plenário da Câmara dos Deputados aprovou o texto-base do projeto de lei que obrigava o uso de máscaras em locais públicos e privados durante a emergência de saúde pública causada pela pandemia de covid-19 (AGÊNCIA 
BRASIL, 2020), imputando ao citadino sanções penais ou multas (que variavam de $R \$ 300$ a $\mathrm{R} \$ 600$ ), além de interdições quanto ao acesso a determinados espaços públicos e privados de uso coletivo. Entretanto, no início de julho, fomos surpreendidos por vetos do Presidente Jair Bolsonaro a alguns trechos/artigos da Lei 14.019, de 2020, que trata do uso obrigatório de máscaras em espaços públicos. Alguns desses vetos referem-se à obrigatoriedade das máscaras em prisões, órgãos e entidades públicas, comércios, indústrias, templos religiosos, instituições de ensino e demais locais fechados em que haja reunião de pessoas (AGÊNCIA SENADO, 2020).

No que se refere à OMS, ressaltamos duas advertências voltadas principalmente à população em geral. A primeira diz respeito ao uso adequado de máscaras médicas:

O uso de máscaras médicas na comunidade pode desviar esse recurso crítico dos profissionais de saúde e de outros que precisam mais deles. Em locais onde as máscaras médicas são escassas, as máscaras médicas devem ser reservadas para profissionais de saúde e indivíduos em risco, quando indicado. (World Health Organization, 2020a, p. 8 - tradução dos autores)

Já a segunda (Figura 08), com print screen da figura online para efeito de documentação, responde de modo objetivo ao que grande parte da população deve ter como dúvida - o uso de máscara de tecido não-médica:

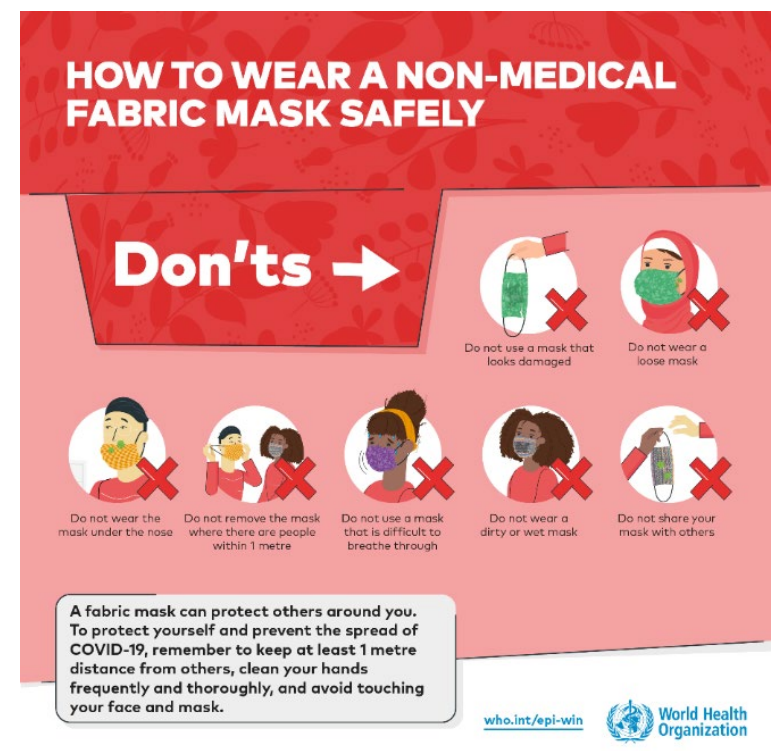

Figura 08: Uso da "máscara caseira" para proteção ao COVID19 segundo a OMS

Fonte: World Health Organization, 2020b. 
O Ministério da Saúde do Brasil igualmente coloca para o público em geral recomendações sobre como se proteger da COVID-19 e, no tocante ao uso de máscaras, recomenda: "Utilize máscaras caseiras ou artesanais feitas de tecido em situações de saída de sua residência" (MINISTERIO DA SAUDE, 2020).

Ainda que o uso de máscaras não garanta em cem por cento a não contaminação pelo vírus - produzindo naqueles que as usam uma falsa sensação de total segurança -, a sua obrigatoriedade ressignifica aquelas áreas interditadas a determinados indivíduos/segmentos sociais. Sem dúvida, há insubordinações ou justificativas as mais variadas (incômodo por ela provocada, rinite, esquecimento, etc.) entre os que deixam de portá-las. A esses, cuja aquisição das mesmas não se configura como problema ou obstáculo, a questão será facilmente resolvida, caso sanções mais duras sejam previstas pois, como dizem, quando "doer no bolso todo mundo vai usar". Por outro lado, interdições mais severas - que poderão resvalar para atitudes de segregação ou banimento das ruas da cidade - estarão voltadas para uma outra categoria de sem-máscaras, composta por indivíduos que, historicamente, sofrem processos de segregação/discriminação no espaço urbano, sendo vistos como uma mancha, um estorvo, uma chaga - são eles os semteto, a população em situação de rua.

Até então, estratégias evacuantes - materializadas numa arquitetura hostil vinham se proliferando em determinadas cidades do mundo (sobretudo em suas áreas mais nobres) para evitar/interditar o acesso e permanência desses usuários em certos espaços. Tornaram-se bastante comuns, por exemplo, os bancos com divisórias, impedindo que se deitem. Cox e Cox $(2015$, p. 11) igualmente atentam para estas "superfícies urbanas vazias potencialmente ocupáveis pela população de rua, como parapeitos de janelas, jardineiras, muretas, áreas cobertas por pontes ou viadutos etc., preenchidas com elementos que impingem sofrimento ao corpo". A arquitetura hostil, por si só, já fala. Não há necessidade de placas ou cordão de isolamento, tampouco de seguranças impedindo o acesso (ainda que, em algumas circunstâncias, tudo isso seja feito).

Quando, além de sem-teto, ou da classificação como "população em situação de rua", estes passam a receber outro estigma - qual seja, de "sem-máscaras"- as advertências e interdições verbais se generalizam, materializadas nos avisos aos incautos através de placas, na abordagem de seguranças, ou, no limite, na retirada compulsória do espaço por descumprimento de norma. Eles que, de certo modo, já se encontram familiarizados com aquilo a que Flusty (1997) denominou de "prickly spaces" (espaços espinhosos) - como os bancos já mencionados anteriormente - precisam lidar agora, em função da falta de máscaras, com os "jittery spaces" (espaços nervosos) mantidos sob vigilância constante seja por câmeras, seja por agentes de segurança (públicos ou privados), seja ainda pela população em geral, que tem sido orientada pelo Poder Público a fiscalizar o cumprimento das orientações para combate à pandemia, criando-se, inclusive, linhas diretas de "disque aglomeração". Sem máscaras, eles não somente maculam a paisagem de uma cidade que deseja se vender, atrair turistas, mostrar-se limpa. Sem máscaras, eles são casos de saúde pública. A pandemia tende, mais uma vez, a retirar da questão social seu caráter político, convertendo-a em "caso de polícia", explicitando, igualmente, sua dimensão espacial. A 
pandemia tende, na mesma medida, a evidenciar as "classes perigosas". Para melhor compreensão deste processo, podemos recorrer a Bauman:

As "classes perigosas" originais eram constituídas por gente "em excesso", temporariamente excluída e ainda não reintegrada, que a aceleração do progresso econômico havia privado de "utilidade funcional", e de quem a rápida pulverização das redes e vínculos retirava, ao mesmo tempo, qualquer proteção. As novas classes perigosas são, ao contrário, aquelas consideradas incapacitadas para a reintegração e classificadas como não-assimiláveis, porque não saberiam se tornar úteis nem depois de uma "reabilitação". Não é correto dizer que estejam "em excesso": são supérfluas e excluídas de modo permanente. (BAUMAN, 2009, p. 22. Grifos do autor)

No contexto da COVID-19, estas classes não-assimiláveis - à medida que não dispõem de meios adequados para protegerem-se do vírus - transmutam-se automaticamente em vetores da doença e tornam-se suas maiores vítimas. Embora a premissa generalizada é de que o vírus é "democrático", posto que é capaz de infectar a todos, independentemente de classe social, sabemos que há grupos e áreas da cidade onde ele costuma encontrar melhores condições de contágio, provocando, igualmente, uma maior taxa de mortalidade - inclusive pela impossibilidade de acesso ao básico para proteção ante a um inimigo tão letal, bem como pela ausência de investimentos do Estado em saúde pública.

Mesmo na maior economia do mundo e onde, até o momento (11/07/2020), foi verificado o maior contingente de mortos em decorrência da SARS-CoV-2, algumas medidas bastante polêmicas têm sido adotadas. Uma delas foi divulgada no dia 31/03 e causou muitas críticas dentro e fora dos EUA:

Como forma de prevenir a transmissão do novo coronavírus, um estacionamento na cidade de Las Vegas, nos Estados Unidos, foi transformado em um "dormitório" ao ar livre para pessoas em situação de rua. A medida, altamente criticada nas redes sociais, foi tomada após o fechamento de um abrigo público onde um dos frequentadores teve confirmada infecção pela covid-19. (NOTÍCIAS UOL, 2020).

Ainda em relação à população em situação de rua, especificamente, cuja permanência nas ruas da cidade depende do recurso a estratégias de "viração" (como pedido de dinheiro para compra de comida a transeuntes, abordagem a donos de restaurantes para solicitação de sobras de refeições, venda de objetos usados, etc.), vimos presenciando uma alteração de comportamento, tanto por parte dos que se encontram nesta condição, quanto da população que por eles é abordada. Como o medo do contágio é grande, percebemos que existe uma tentativa de distanciamento efetivo de quem circula pelas ruas em relação aos que nelas "vivem", chegando à prática da mudança de calçada. Por outro lado, parte da população em situação de rua, ao invés de pedir dinheiro para alimentação, simplesmente o pede para compra da "capinha" (expressão utilizada, no Rio 
de Janeiro, para se referirem à máscara). Talvez seja esta uma forma de deixarem claro que, sem elas, não conseguirão sobreviver no espaço urbano.

\section{Reflexões Finais: dúvidas e hesitações}

$\mathrm{Na}$ tragédia cotidiana que se tornou a COVID19, a população mundial segue bailando - seja à deriva, seja ancorada nos avanços científicos e tecnológicos - em direção a um futuro mascarado e incerto. Descobriremos uma vacina que seja eficiente para evitar a propagação do vírus? Por quanto tempo durarão as medidas de isolamento social e como seremos afetados por elas? A pandemia terá o poder de nos fazer repensar sobre a vida e a morte, sobre a desigualdade social, sobre o respeito à natureza, sobre empatia e solidariedade? E as máscaras - que ao longo da história sempre tiveram lugar - que marcas deixarão no século XXI? Que estratégias adotaremos doravante nos espaços públicos e privados de uso coletivo vestidos como bons caçadores ou inaptos?

\section{Referências}

AGÊNCIA SENADO. Em novo veto, governo desobriga uso de máscaras em presídios. Disponível em: https://www12.senado.leg.br/noticias/materias/2020/07/06/em-novoveto-governo-desobriga-uso-de-mascaras-em-presidios. Acesso em: 08 jul. 2020.

ALTUNA, B. El individuo y sus máscaras. Ideas y Valores, Bogotá, 140, p. 33-52, 2009. Disponível em:

$<$ https://revistas.unal.edu.co/index.php/idval/article/view/36475/38395::pdf. $>$. Acesso em: 23 abr. 2020.

BAUER, C. Plague doctor - Venice Carnival (foto). Disponível em:

$<$ https://1.bp.blogspot.com/-

vtsfjawgSZY/Vrur0tNX7cI/AAAAAAAARaA/QuTcnmDk6zA/s400/plague\%2Bdoctor \%2BPhoto\%2BCat\%2BBauer.jpg >. Acesso em: 23 abr. 2020.

BERTRAND, G. Histoire du Carnaval de Venise - Xie-XXIe siècle. Paris: Pygmalion, 2013.

CARLOS, A. F. A. As Faces da Desigualdade Socioespacial Imuminadas pela Crise da Covid-19. Ensaios, São Paulo, IEA/USP, p. 1-6, 2020. Disponível em:

$<\mathrm{http} / / / \mathrm{www}$.iea.usp.br/publicacoes/ensaios/as-faces-da-desigualdade-social-iluminadaspela-crise-da-covid-19

COX, E. P., COX, M. I. P. Interdições ao corpo no corpo da cidade: arquitetura, urbanismo, discurso e controle social. Linguasagem, São Carlos, v. 24, n. 1, p. 1-15, 2015. Disponível em: $<$ http://www.linguasagem.ufscar.br/index.php/linguasagem/article/view/161/130>. Acesso em: 23 abr. 2020. 
CRISTALDO, H. Deputados aprovam uso obrigatório de máscara em locais públicos. Agência Brasil, 19 maio 2020. Disponível em: <

https://agenciabrasil.ebc.com.br/politica/noticia/2020-05/deputados-aprovam-usoobrigatorio-de-mascara-em-locais-publicos>. Acesso em: 22 maio 2020.

>. Acesso em: 18 maio 2020.

DANI, S. A máscara, seu sentido e seu uso no treinamento do ator. Porto Arte, Porto Alegre, v. 1, n. 1, p. 83-90, 1990. Disponível em:

$<$ https://seer.ufrgs.br/PortoArte/article/view/27326/15836>. Acesso em: 10 maio 2020.

DEOLHONOFUTURO.UNINTER. Pandemia no Brasil: memes se sobressaem às notícias. Disponível em: $<$ https://deolhonofuturo.uninter.com/pandemia-no-brasilmemes-se-sobressaem-as-noticias/>. Acesso em: 18 maio 2020.

ECO, U. “O hábito fala pelo monge”. In: ECO, U. (Org.). Psicologia do Vestir. São Paulo: Assírio e Alvim, 1989, p. 7-21.

EILPERIN, J., STEIN, J., BUTLER, D., HAMBURGER, T. U.S. sent millions of face masks to China early this year, ignoring pandemic warning signs. The Washington Post, Washington D.C., 18 abr. 2020. Health. Disponível em:

$<$ https://www.washingtonpost.com/health/us-sent-millions-of-face-masks-to-chinaearly-this-year-ignoring-pandemic-warning-signs/2020/04/18/aaccf54a-7ff5-11 ea-80131b6da0e4a2b7_story.html>. Acesso em: 23 abr. 2020.

ESPACEFRANCAIS. Les Masques au Théâtre. Disponível em: $<$ https://www.espacefrancais.com/les-masques-au-theatre/>. Acesso em: 15 abr. 2020.

FLUSTY, S. Building Paranoia. In: ELLIN, N. Architecture offear. New York: Princenton Architectural Press, 1997. p. 47-61.

GOFFMAN, E. Comportamento em Lugares Públicos. Petrópolis: Vozes, 2010.

KLINTOWITZ, J. Máscaras Brasileiras. São Paulo: Raízes Gráficas Ltda/Rhodia, 1986.

LYCEEDADULTES. Elements d'Histoire $d u$ Theatre: le theatre antique. Disponível em: $<$ https://www.lyceedadultes.fr/sitepedagogique/documents/francais/francais $1 \mathrm{~S} />$. Acesso em: 15 abr. 2020.

MAIA, C. E. S. Ritual e Emoção nas Interações Espaciais - repensando o espaço sagrado nas festas populares de romarias e folguedos. In: ROSENDAHL, Z. (Org.). Trilhas do Sagrado. Rio de Janeiro: EdUERJ, 2010. p. 87-112.

MELCHIOR, M. R. Research Approaches to the Study of Dress and Fashion. Creative Encounters Working Papers, Copenhagen, \#19, p. 1-18, 2008. Disponível em:

$<$ https://openarchive.cbs.dk/bitstream/handle/10398/7766/Creative\%20Encounters\%20 Working\%20Papers\%2019.pdf?sequence=1>. Acesso em: 18 abr. 2020. 
MINISTÉRIO DA SAÚDE. Sobre a Doença - Como se proteger. Disponível em: $<$ https://coronavirus.saude.gov.br/sobre-a-doenca\#como-se-proteger>. Acesso em: 20 abr. 2020.

G1-GLOBO. Profissionais da saúde reclamam da falta de equipamentos de proteção individual. Disponível em: < https://g1.globo.com/jornal-

nacional/noticia/2020/04/11/profissionais-da-saude-reclamam-da-falta-de-equipamentosde-protecao-individual.ghtml>. Acesso em: 23 abr. 2020.

MOREIRA, V. Da Máscara à pessoa: a concepção trágica de homem. Revista Brasileira de Ciências Sociais, Fortaleza, n. 1/2, p. 21-31, 1994. Disponível em: $<$ http://www.rcs.ufc.br/edicoes/v25n12/rcs_v25n12a2.pdf $>$. Acesso em: 8 abr. 2020.

MOTTA, F. Coveiros do Cemitério do Caju usam equipamentos de proteção para enterrar um idoso que morreu de Covid-19. O Globo, Rio de Janeiro, 4 abr. 2020. Rio. Disponível em: $\quad<$ https://oglobo.globo.com/rio/sem-velorio-com-caixoes-lacradoscoronavirus-impoe-isolamento-ate-no-luto-muda-rotina-em-cemiterios-1-24350944>. Acesso em: 8 abr. 2020.

OLIVEIRA, R. A. Máscaras: Egito Antigo. Corpo e Sociedade, 12. Disponível em: $<$ https://corpoesociedade.blogspot.com/2016/01/mascaras-egito-antigo.html $>$. Acesso em: 8 abr. 2020.

PAIVA, C. E. Tropa de choque alternativa - Protestos no Rio de Janeiro. 2013. Rua da Foto. Disponível em:

$<$ https://www.ruadafotocintiaerdens.com/p779322117/h64f9454a\#th64f9454a>. Acesso em: 23 abr. 2020.

RIO DE JANEIRO (Estado). Projeto de Lei No 1239/2008. Ementa: Proíbe no âmbito do Estado do Rio de Janeiro o uso de máscaras de fantasia denominada "clóvis" ou "bate bola" e dá outras providências. ALERJ, Estado do Rio de Janeiro, 11 fev. 2008. 2008a. Disponível em:

$<$ http://alerjln1.alerj.rj.gov.br/scpro0711.nsf/d9b480027c6a3c4d83257258006de468/c5a 6526dbcf7faa0832573ec00498a66?OpenDocument>. Acesso em: 20 maio 2020.

RIO DE JANEIRO (Estado). Parecer da Comissão de Constituição e Justiça ao Projeto de Lei No 1239/2008. ALERJ, Estado do Rio de Janeiro, 26 fev. 2008. 2008b. Disponível em: $<$ http://alerjln1.alerj.rj.gov.br/scpro0711.nsf/e00a7c3c8652b69a83256cca00646ee5/a eafc17da53d2aa1832573f30050f992?OpenDocument>. Acesso em: 20 maio 2020.

RIO DE JANEIRO (Estado). Lei n ${ }^{\circ} 6528$ de 11 de setembro de 2013 - regulamenta o artigo 23 da Constituição do estado. Rio de Janeiro, 11 set. 2013. Disponível em: $<$ https://gov-rj.jusbrasil.com.br/legislacao/1036049/lei-6528-13> Acesso em: 20 maio 2020.

SIMMEL, G. As grandes cidades e a vida do espírito. Mana - Estudos de Antropologia Social, Rio de Janeiro, v. 11, n. 2, p. 577-591, 2005. Disponível em:

$<$ http://www.scielo.br/pdf/mana/v11n2/27459.pdf > . Acesso em: 10 abr. 2020. 
SOUZA, G. de. Bloco de Carnaval Céu na Terra em Santa Teresa. O Dia na Folia. 15 fev. 2020. Disponível em:

$<$ https://odia.ig.com.br/_midias/jpg/2020/02/15/1200x675/1_g5i6494_1015675325.jpg>. Acesso em: 23 abr. 2020.

SOUZA, M. L. Da "diferenciação de áreas" à "diferenciação socioespacial": a "visão (apenas) de sobrevôo" como uma tradição epistemológica e metodológica limitante. Cidades, Presidente Prudente, v. 4, n. 6, p. 101-114, jan./dez., 2007. Disponível em: https://revista.fct.unesp.br/index.php/revistacidades/article/view/573. Acesso em 23 de abril de 2020.

STUDYLIBFR. Le Theatre Antique. Disponível em:

$<$ https://studylibfr.com/doc/5434535/les-costumes-et-masques-du-theatre-antique>. Acesso em: 15 abr. 2020.

THEATRONS. Le Théâtre Antique - Les drames grecs et romains sont souvent considérés comme les premières formes du théâtre. Disponível em:

$<$ http://www.theatrons.com/theatre-antique.php>. Acesso em: 10 abr. 2020.

THEMASCHERADE. Le Médicin de la Peste. Disponível em:

$<\mathrm{http}: / /$ themascherade.com/contents/fr/d5_Page_5.html.>. Acesso em: 15 abr. 2020.

THIEME, O. C., EICHER, J. B. African dress: form, action, meaning. Africana Publishing, University of Minnesota Digital Conservancy, p. 115-138, 1987.

Disponível em: <http://hdl.handle.net/11299/162432>. Acesso em: 18 abr. 2020.

NOTÍCIAS UOL Coronavirus. Pessoas em situação de rua são 'alojadas' em estacionamento nos EUA... - Disponível em:

$<$ https://noticias.uol.com.br/internacional/ultimas-noticias/2020/03/31/pessoas-emsituacao-de-rua-sao-alojadas-em-estacionamento-nos-eua.htm?cmpid=copiaecola $>$. Acesso em: 12 maio 2020.

VAUBAN, F. Focus sur ... Le costume du médecin de la peste. Foto Hôpital NotreDame à la Rose. Disponível em: <https://www.museumpassmusees.be/fr/articles/focussur-le-costume-du-medecin-de-la-peste>. Acesso em: 15 abr. 2020.

WIRTH, L. O urbanismo como modo de vida. In: Velho, O.G (Org.). O fenômeno urbano. Rio de Janeiro: Zahar; 1973. p. 90-113.

WORLD HEALTH ORGANIZATION. Advice on the use of masks in the context of COVID-19 - Interim guidance. 2020a. Disponível em:

$<$ https://www.who.int/publications-detail/advice-on-the-use-of-masks-in-thecommunity-during-home-care-and-in-healthcare-settings-in-the-context-of-the-novelcoronavirus-(2019-ncov)-outbreak>. Acesso em: 10 jul. 2020.

WORLD HEALTH ORGANIZATION. How to wear a non-medical fabric mask safely. 2020b Disponível em: <https://www.who.int/images/default-source/healthtopics/coronavirus/clothing-masks-infographic---web---part2.png?sfvrsn=d7b0f88d_20>. Acesso em: 10 jul. 2020. 


\section{Rosemere Maia}

Professora Titular na Escola de Serviço Social da Universidade Federal do Rio de Janeiro.

Doutora em Geografia pela UFRJ, Estágios Seniores/Pós-Doutorados pela Universidade de Coimbra, Universidade Nova de Lisboa e Pontifícia Universidade Católica do Rio de Janeiro.

Endereço institucional: Escola de Serviço Social. Av. Pasteur, 250/fundos, Praia Vermelha, Rio de Janeiro- Rio de Janeiro- Brasil. CEP 22290-902

ORCID 0000-0001-5053-9571

rosemaia@terra.com.br

\section{Carlos Eduardo Santos Maia}

Professor Titular na Universidade Federal de Juiz de Fora/Instituto de Ciências Humanas/Departamento de Geografia.

Doutor em Geografia pela UFRJ, Estágio Sênior/Pós-Doutorado pela Sorbonne Paris IV.

Endereço Institucional: UFJF/ICH/DEGEO. Campus Universitário, Rua José Lourenço Kelmer, s/n, São Pedro, Juiz de Fora - Minas Gerais - Brasil. CEP 36036900

ORCID 0000-0002-2035-4362

calrmaia@uol.com.br

Recebido para publicação em maio de 2020

Aprovado para publicação em junho de 2020 